\title{
SISTEMAS AGROFLORESTAIS CAFEEIRO-ARAUCÁRIA E SEU EFEITO NA MICROBIOTA DO SOLO E SEUS PROCESSOS
}

\section{AGROFORESTRY SYSTEM COFFEE-ARAUCARIA AND ITS EFFECT ON SOIL MICROBIOTA AND THEIR PROCESSES}

\author{
Rogério Melloni ${ }^{1}$ Natália Rodrigues Costa ${ }^{2}$ Eliane Guimarães Pereira Melloni ${ }^{1}$ \\ Maria Cristina Silva Lemes ${ }^{2}$ Maria Inês Nogueira Alvarenga ${ }^{1}$ José Nunes Neto ${ }^{3}$
}

\section{RESUMO}

Os efeitos de sistemas agroflorestais (SAFs) na qualidade do solo têm sido estudados. No entanto, faltam informações sobre o sistema cafeeiro-araucária, presente em alguns ambientes. Com o objetivo de avaliar a qualidade do solo e sua microbiota nesses sistemas e, considerando a existência de SAF de cafeeiro sob dois níveis de sombreamento por araucária (mediano - CSM, intenso - CSI), além do cultivo a sol pleno (CSP), na região sul de Minas Gerais, amostras de solo foram retiradas dessas três subáreas para determinação de atributos químicos, físicos e, principalmente, microbiológicos e bioquímicos (densidade de bactérias e fungos, solubilizadores de fosfato, microrganismos celulolíticos, amonificantes, desnitrificantes, comprimento de micélio extrarradicular total de fungos micorrízicos arbusculares - MAs, densidade de esporos de fungos MAs, porcentagem e intensidade de colonização radicular, carbono da biomassa microbiana, atividade microbiana e quociente metabólico). O sistema agroflorestal cafeeiro-araucária não afetou a distribuição dos grupos microbianos estudados, mas o sombreamento mediano proporcionou maior acúmulo de matéria orgânica no solo, com efeito positivo nos seus atributos físicos e maior formação de micorriza no cafeeiro.

Palavras-chave: microrganismos do solo; micorriza; Araucaria angustifolia; Coffea arabica.

\section{ABSTRACT}

The effects of agroforestry system (AFS) on soil quality have been studied. However, there is lack of information about the coffee-araucaria system, present in some environments. In order to evaluate the soil quality and its microbiota in these systems and, considering the existence of AFS coffee under two levels of shading by Araucaria (median - CSM, intense - CSI), and the growing in full sun (CSP), in the southern of Minas Gerais state, soil samples were taken from three areas in the summer of 2009 to determine the physical, chemical, and especially microbiological and biochemical attributes (density of bacteria and fungi, phosphate solubilizing, cellulolytic microorganisms, ammonifying microorganisms, denitrifying, total length of extraradical mycelium of arbuscular mycorrhizal - AM - fungi, density of fungal spores, percentage and intensity of root colonization, microbial biomass carbon, microbial activity and metabolic quotient). The coffee-araucaria agroforestry system did not affect the distribution of the microbial groups studied, but the median shading provided a greater accumulation of organic matter in the soil, with a positive effect on its physical attributes and greater mycorrhiza formation in coffee.

Keywords: soil microorganisms; mycorrhiza; Araucaria angustifolia; Coffea arabica.

1 Engenheiro Agrônomo, Dr., Professor Associado da Universidade Federal de Itajubá, Campus Itajubá, Av. BPS, 1303, Bairro Pinheirinho, CEP 37500-903, Itajubá (MG), Brasil. rogerio.melloni@gmail.com / eliane.melloni@ gmail.com / minesalvarenga@gmail.com

2 Engenheira Ambiental, Universidade Federal de Itajubá, Campus Itajubá, Av. BPS, 1303, Bairro Pinheirinho, CEP 37500-903, Itajubá (MG), Brasil.natrcosta@yahoo.com.br / tina.lemes@hotmail.com

3 Engenheiro Ambiental, Mestre em Ciências em Meio Ambiente e Recursos Hídricos, Universidade Federal de Itajubá, Campus Itajubá, Av. BPS, 1303, Bairro Pinheirinho, CEP 37500-903, Itajubá (MG), Brasil. neto_unifei@, yahoo.com.br

Recebido para publicação em 30/03/2013 e aceito em 4/05/2017

Ci. Fl., v. 28, n. 2, abr. - jun., 2018 


\section{INTRODUÇÃO}

Os sistemas agroflorestais (SAFs) são alternativas de uso e manejo dos recursos naturais, nos quais espécies lenhosas são utilizadas em associação com culturas agrícolas, de maneira simultânea ou em sequência temporal, com interações ecológicas e/ou econômicas significativas entre os componentes, podendo-se constituir em prática recomendável nas várias regiões do Brasil (GAMA RODRIGUES, 2006). Em regiões tropicais, a maioria das espécies agrícolas é cultivada em sistema de monocultura, mas muitas espécies são tolerantes a certos níveis de sombreamento, adaptando-se a sistemas de cultivo mistos (ILANY et al., 2010).

Em SAFs, segundo Fassbender (1993), as espécies arbóreas, além de interceptarem a água da chuva e aumentarem a infiltração, podem diminuir a evaporação e permitir ao café uma melhor condição ecológica. Além disso, devido às menores perdas por lixiviação e acúmulo de matéria orgânica no solo (CORREIA; ANDRADE, 2004), há manutenção de condições microclimáticas mais adequadas para a microbiota do solo (BABBAR; ZAK, 1994).

Os mecanismos fisiológicos responsáveis pelas diferenças entre as plantas adaptadas à sombra e ao sol ainda não estão muito bem esclarecidos. O cafeeiro é atualmente conduzido segundo dois sistemas de cultivo: a pleno sol, predominante no Brasil; e o sombreado, como na Colômbia, onde o sombreamento é uma prática tradicional, em zonas cujas condições de solo e clima não são favoráveis à cultura (CHAMORRO; GALLO; LÓPEZ, 1994).

Apesar da pouca tradição no cultivo de café em SAFs, algumas pesquisas mostram a possibilidade dessa prática alcançar êxito em determinados locais do país, já que, em condições naturais, o café busca a sobrevivência através do equilíbrio entre a frutificação e o crescimento (MATSUMOTO, 2004).

Matiello et al. (1985) concluíram que o café da variedade Catuaí, testado em diferentes intensidades de sombreamento, teve maior produtividade com 50 e $75 \%$ de sombra e a menor produção foi obtida com o cultivo de café a pleno sol. Para Matiello (1995), o sombreamento promove uma maior estabilidade de produção no decorrer dos anos, evitando picos de alta produtividade em anos alternados. No entanto, há uma tendência de redução da produtividade média, que é compensada pela regularização da produção, permitindo melhores previsões por parte do produtor. Segundo Ricci et al. (2006), o sombreamento com banana e Erythrina verna reduziu o diâmetro dos cafeeiros, o número de ramos produtivos e de nós por ramos, mas aumentou a área foliar e o peso dos grãos, permitindo a obtenção de produção semelhante ao cultivo a pleno sol. Lunz (2006) não observou a existência de um nível de radiação ótimo para o crescimento e produtividade do café, mas níveis moderados de sombreamento, com radiação entre 20 e $30 \%$, podem ser considerados mais adequados para a cultura do cafeeiro, pois não prejudicam o crescimento das plantas e proporcionam melhor qualidade dos frutos.

Mas o sombreamento não afeta somente a cultura. Em virtude da diversidade de plantas e adição de matéria orgânica, o solo e seus atributos também são afetados, contribuindo para variação em sua qualidade. Segundo trabalhos clássicos de Haag (1975) e Young (1976), os solos e a vegetação estão intrinsecamente relacionados. O principal atributo físico do solo afetado pela quantidade de matéria orgânica e raízes (WOHLENBERG et al., 2004) é a agregação, o que consequentemente, promove melhorias em outros atributos como a porosidade, a aeração, a capacidade de retenção de umidade, entre outras (BAYER; MIELNICZUK, 2008).

A alteração do ambiente solo influencia diretamente a microbiota do solo e seus processos (DORAN; ZEISS, 2000; MELLONI et al., 2008). Estudos de microrganismos com atividades específicas, envolvidos nos ciclos do $\mathrm{C}$ como os celulolíticos, do $\mathrm{N}$ como os amonificantes e desnitrificantes e do $\mathrm{P}$, como os solubilizadores de fosfato e fungos micorrízicos arbusculares e suas estruturas (ZANGARO et al., 2007; BONFIM et al., 2010; MELLONI et al., 2013), em parceria com a quantificação de bactérias e fungos totais do solo (atividades não específicas), ajudam a entender como os processos bioquímicos ocorrem e servem de indicador de impactos de diferentes atividades antrópicas.Considerando, ainda, os papéis dessas estruturas na eficiência da associação com as espécies vegetais, pode-se inferir que sua quantificação é altamente desejável para obter um conhecimento amplo de todo o sistema simbiótico (MELLONI et al., 
2001). A análise de atributos microbiológicos com alto potencial de serem utilizados como indicadores de qualidade dos solos permite avaliar e identificar as melhores estratégias adotadas em SAFs, visando, não somente à produtividade do cafeeiro, mas também a qualidade e sustentabilidade ambiental.

Em cafeeiro cultivado sobmanejo orgânico(adubos orgânicos diversos) ou convencional(fertilizantes de solo e foliares), Theodoro (2006) observou que não houve diferença na biomassa microbiana em ambos os manejos, mas que no orgânico a diversidade de fungos MAs foi maior. Com resultados semelhantes, Martins (2003), avaliando o efeito de diferentes coberturas vegetais (bananeira, mamona, pau-pereira, entre outras espécies de crescimento espontâneo) nos atributos carbono da biomassa microbiana e colonização micorrízica, também não observou diferença significativa entre os agroecossistemas. Em contrapartida, Cunha et al. (2005) relataram maiores valores da biomassa e da respiração basal do solo para sistemas orgânicos de produção de café em comparação com sistemas convencionais. Também Colozzi Filho et al. (2000) observaram maiores valores de biomassa microbiana quando foram cultivadas leguminosas de verão (mucuna-anã e amendoim-cavalo). Uma revisão sobre a ocorrência de fungos MAs e seus benefícios ao cafeeiro pode ser encontrada em Andrade et al. (2009).

Apesar dos impactos do manejo e da cobertura vegetal em atributos microbiológicos e bioquímicos do solo serem alvos de muitas pesquisas, não há estudos relacionados ao sistema café consorciado com araucária. No entanto, Melloni et al. (2008), avaliando o efeito de diferentes coberturas vegetais (eucalipto, araucária, pasto e mata nativa) em atributos do solo, observaram maior atividade microbiana em solo sob araucária, o qual apresentava maior teor de matéria orgânica e menor fertilidade. Tal resultado indica o potencial da araucária em contribuir para a sua utilização em sombreamento de café. Este fato pode ser aliado ao micotrofismo da araucária, que pode intensificar a densidade e diversidade de fungos MAs, conforme estudos de Moreira-Souza et al. (2003) e Moreira-Souza e Cardoso (2002), Andreazza et al. (2008) e Andrade et al. (2009).

Nesse sentido, este trabalho tem por objetivo quantificar o efeito do sistema agroflorestal cafeeiroaraucária, sob duas intensidades de sombreamento, na qualidade do solo e sua microbiota, fornecendo informações para a avaliação ambiental desses agroecossistemas.

\section{MATERIAL E MÉTODO}

A área de estudo abrange uma lavoura de café da variedade Catuaí Vermelho plantada em 1973, em sub-bosque de araucária (Araucaria angustifolia (Bertol.) Kuntze) plantada em 1976, em um Argissolo Vermelho Distrófico textura média relevo ondulado, dentro do município de Pedralva-MG (22¹4'34"S, $45^{\circ} 27^{\prime} 57^{\prime}$ 'W), a $911 \mathrm{~m}$ de altitude e clima tropical de altitude. A temperatura média anual em Pedralva é $19,5^{\circ} \mathrm{C}$, sendo $22,3^{\circ} \mathrm{C}$ para o mês de janeiro e $15,5^{\circ} \mathrm{C}$ para julho, com pluviosidade média de $1474 \mathrm{~mm}$.

Até 2006, foi aplicado manejo convencional na cultura, sendo posteriormente substituído por manejo orgânico. Para fins de estudos, essa área foi dividida em três subáreas com 0,4 ha cada, conforme os tratamentos, considerando-se o grau de sombreamento: cafeeiro com sombreamento intenso (CSI), cafeeiro com sombreamento médio (CSM) e cafeeiro a sol pleno (CSP), conforme descrito em Oliveira et al. (2016). Os pés de café foram plantados com espaçamento de 4,0 m entre linhas e 2,5 m entre plantas, nas glebas CSM e CSI; e 2,0 m entre linhas e 1,25 m entre plantas na gleba CSP. Já as araucárias apresentam espaçamento de 8,0 m entre linhas e 4,0 m entre plantas na gleba CSM; e 4,0 m entre linhas e 4,0 $\mathrm{m}$ entre plantas na gleba CSI. No presente ensaio, foi utilizado o delineamento inteiramente casualizado, considerando-se a pequena dimensão da área e subáreas e o declive pouco acentuado.

Cada subárea foi dividida em três parcelas (consideradas repetições) e em cada parcela foram retiradas amostras deformadas por meio de enxada desinfestada com água e álcool, e indeformadas por meio de anel de Uhland. Em cada parcela, foi retirada uma amostra composta por três amostras simples de solo (contendo raízes), a qual ocorreu no final do verão de 2009. As amostras simples foram retiradas em ziguezague, na profundidade de 0 a $10 \mathrm{~cm}$, a $20 \mathrm{~cm}$ do caule da planta de café, com retirada da serapilheira. Parte das amostras deformadas de solo foi peneirada em malha de $2 \mathrm{~mm}$, antes do acondicionamento a $4^{\circ} \mathrm{C}$ até a avaliação dos atributos microbiológicos e bioquímicos de interesse. Da amostra restante, foram separadas as raízes finas, com posterior manutenção em solução de álcool a 70\% em frascos plásticos, para determinação da colonização radicular. Outra parte das amostras deformadas de solo foram secas e subme-

Ci. Fl., v. 28, n. 2, abr. - jun., 2018 
tidas à caracterização química e física, determinando-se: a) de amostras deformadas - $\mathrm{pH}, \mathrm{P}$, soma de bases (SB), capacidade de troca catiônica total $(\mathrm{T})$ e efetiva $(\mathrm{t})$, saturação por bases $(\mathrm{V})$, saturação de $\mathrm{Al}(\mathrm{m})$ e matéria orgânica (MO), estabilidade de agregados por via úmida, calculando-se, posteriormente, o diâmetro médio geométrico (DMG) e ponderado (DMP) dos agregados; b) de amostras indeformadas: densidade do solo e volume total de poros (macro e microporosidade). Todas essas metodologias estão descritas em Embrapa (1997).

As seguintes análises microbiológicas e bioquímicas foram realizadas, sendo as metodologias descritas em Melloni et al. (2001), Melloni, Siqueira e Moreira (2003) e Carneiro et al. (2008): densidade de bactérias e fungos pelo método do plaqueamento por gotas, densidade de solubilizadores de fosfato em meio com fosfato insolúvel, densidade de microrganismos celulolíticos em meio líquido com celulose, densidade de amonificantes em meio ácido casamino, densidade de desnitrificantes por meio de coloração com reagente difenilamina (ULBRICH et al., 2004), comprimento de micélio extrarradicular total de fungos MAs, densidade de esporos de fungos MAs, porcentagem e intensidade de colonização radicular, carbono da biomassa microbiana pelo método da irradiação/incubação, por meio de micro-ondas, atividade microbiana (respiração basal) pelo método da captura do $\mathrm{CO}_{2} \mathrm{em} \mathrm{NaOH}$, e determinação do quociente metabólico $\left(q \mathrm{CO}_{2}\right)$ pela razão entre atividade microbiana e carbono da biomassa microbiana.

Os resultados dos atributos microbiológicos foram submetidos à análise de variância pelo teste $\mathrm{F}$, com comparação de médias por Duncan a 5\% de significância, por meio do programa estatístico SANEST, após análise da homocedasticidade das variâncias, com transformação dos dados de porcentagem de colonização radicular para arcsen (raiz de x/100), intensidade de colonização para raiz $(x+100)$ e densidade de esporos para raiz x. Posteriormente, os valores dos atributos microbiológicos, bioquímicos, físicos e químicos de cada repetição foram utilizados para análise de componentes principais (PCA) por meio do software PC-ORD 3.12.

\section{RESULTADOS E DISCUSSÃO}

As médias dos atributos químicos e físicos determinados nas amostras de solo nos diferentes tratamentos encontram-se na Tabela 1. Menor fertilidade foi observada para o solo do CSM, em relação aos dos demais tratamentos, exceto para teor de matéria orgânica, capacidade de troca catiônica potencial, e os atributos físicos, volume total de poros, densidade do solo, DMG e DMP, maiores no primeiro.

Segundo Bayer e Mielniczuk (2008), a matéria orgânica do solo é responsável pelo aumento na agregação das partículas, contribuindo para aumento da porosidade do solo e melhoria na sua estabilidade, conforme se observou para o CSM. No entanto, a baixa saturação por bases nesse tratamento indica a necessidade de calagem. Severino e Oliveira (1999) observaram que alguns sistemas agroflorestais com café são capazes de fornecer nutrientes para sustentar a produção da lavoura, por meio da decomposição da serapilheira. No entanto, pode-se inferir que o sombreamento do café por araucárias proporciona baixa diversidade vegetal, o que poderia influenciar na qualidade da serapilheira e, consequentemente, na diversidade de nutrientes incorporados ao solo.

Quanto aos atributos microbiológicos, não houve efeito dos sistemas ou do sombreamento do cafeeiro por araucária em grupos microbianos de atividades não específicas (bactérias e fungos) e específicas (envolvidas nos ciclos do $\mathrm{C}, \mathrm{N}$ e $\mathrm{P}$ ) do solo. A adição de material orgânico pelo cafeeiro e araucária nas glebas sombreadas (CSM e CSI) e de cafeeiro e plantas daninhas na gleba CSP contribuíram para uma distribuição homogênea dos microrganismos nas diferentes glebas. Segundo a Comissão de Fertilidade do Solo do Estado de Minas Gerais (1999), o teor de matéria orgânica pode ser considerado médio, e tal fato pode ter proporcionado ambientes satisfatórios ao desenvolvimento microbiano em todas as glebas. 
TABELA 1: Médias e interpretação dos atributos químicos e físicos do solo em sistema agroflorestal cafeeiro-araucária e cafeeiro a pleno sol.

TABLE 1: Averages and interpretation of soil chemical and physical attributes under agroforestry system coffeearaucaria and coffee under full sun.

\begin{tabular}{llll}
\hline Atributos químicos e físicos & CSM & CSI & CSP \\
\hline & \multicolumn{2}{c}{ Atributos químicos } \\
\hline $\mathrm{pH}$, em água & $5,36 \mathrm{c}$ (acidez média) & $6,43 \mathrm{a}$ (acidez fraca) & $6,11 \mathrm{~b}$ (acidez fraca) \\
$\mathrm{P}, \mathrm{mg} \mathrm{dm}^{-3}$ & $10,03 \mathrm{~b}$ (baixo) & $35,12 \mathrm{a}$ (bom) & $81,33 \mathrm{a}$ (muito bom) \\
$\mathrm{SB}, \mathrm{cmol}_{\mathrm{c}} \mathrm{dm}^{-3}$ & $3,48 \mathrm{c}$ (médio) & $6,20 \mathrm{a}$ (muito bom) & $5,10 \mathrm{~b}$ (bom) \\
$\mathrm{t}, \mathrm{cmol}_{\mathrm{c}} \mathrm{dm}^{-3}$ & $4,08 \mathrm{c}$ (médio) & $6,23 \mathrm{a}$ (bom) & $5,18 \mathrm{~b}$ (bom) \\
$\mathrm{T}, \mathrm{cmol}_{\mathrm{c}} \mathrm{dm}^{-3}$ & $10,25 \mathrm{a}$ (bom) & $8,37 \mathrm{~b}$ (médio) & $7,53 \mathrm{~b}$ (médio) \\
$\mathrm{V}, \%$ & $34,46 \mathrm{~b}$ (baixo) & $72,53 \mathrm{a}$ (bom) & $65,33 \mathrm{a}$ (bom) \\
$\mathrm{m}, \%$ & $3,33 \mathrm{a}$ (muito baixo) & $0,00 \mathrm{~b}$ (muito baixo) & $0,00 \mathrm{~b}$ (muito baixo) \\
$\mathrm{MO}, \mathrm{dag} \mathrm{dm}^{-3}$ & $2,70 \mathrm{a}$ (médio) & $2,35 \mathrm{ab}$ (médio) & $2,28 \mathrm{~b}$ (médio) \\
\hline \multicolumn{4}{c}{ Atributos físicos } \\
\hline Volume total de poros, \% & \multicolumn{4}{c}{$40,72 \mathrm{~b}$} \\
$\mathrm{DS}, \mathrm{g} \mathrm{cm}^{-3}$ & $53,38 \mathrm{a}$ & $1,49 \mathrm{a}$ & $41,80 \mathrm{~b}$ \\
$\mathrm{DMG}, \mathrm{mm}$ & $1,23 \mathrm{~b}$ & $3,99 \mathrm{a}$ & $1,51 \mathrm{a}$ \\
$\mathrm{DMP}, \mathrm{mm}$ & $2,98 \mathrm{~b}$ & $4,55 \mathrm{a}$ & $3,27 \mathrm{~b}$ \\
\hline
\end{tabular}

Médias seguidas de mesma letra na linha não diferem entre si pelo teste de Duncan $(\mathrm{p}<0,05)$. Classes de interpretação de fertilidade do solo segundo a Comissão de Fertilidade do Solo do Estado de Minas Gerais (1999). CSI (cafeeiro com sombreamento intenso); CSM (cafeeiro com sombreamento médio); CSP (cafeeiro a sol pleno); pH (potencial hidrogeniônico); SB (soma de bases); t (capacidade de troca catiônica efetiva); T (capacidade de troca catiônica potencial a pH 7); V (saturação por bases); m (saturação em alumínio); MO (matéria orgânica); DS (densidade do solo); DMG (diâmetro médio geométrico); DMP (diâmetro médio ponderado).

As médias dos atributos microbiológicos e bioquímicos obtidas das amostras de solo dos sistemas de estudo estão apresentadas na Tabela 2.

Em se tratando de fungos MAs, microrganismos com atividades específicas, ao contrário dos atributos microbiológicos anteriormente apresentados, houve efeito dos sistemas ou do sombreamento em todos os atributos relacionados às suas estruturas, mostrando a sua elevada capacidade discriminatória dos ambientes e sensibilidade como indicadores de qualidade ambiental. Tanto o cafeeiro quanto a araucária são considerados micotróficos e, portanto, podem sofrer importantes influências positivas de fungos MAs no desenvolvimento (ANDREAZZA et al., 2008; ANDRADE et al., 2009). Exceto para densidade de esporos, com maior valor obtido no CSP, os maiores valores de comprimento de micélio extrarradicular total, porcentagem e intensidade de colonização radicular foram obtidos no sistema agroflorestal CSM, comparados aos demais.

A alta densidade de esporos no CSP contraria os resultados obtidos por Bonfim et al. (2010), os quais estudaram a influência da arborização de cafezais (Plathymenia reticulata, Inga edulis ou Persea americana Mill. ou fragmento de mata nativa) sobre a população de esporos de fungos MAs, e observaram menor densidade ( 274 esporos $100 \mathrm{~g}^{-1}$ de solo) e baixa viabilidade em solo sob cafeeiro cultivado a pleno sol. A menor densidade de esporos observada em sistemas agroflorestais pode estar relacionada, ainda, à baixa profundidade de amostragem $(10 \mathrm{~cm})$ de solo para este estudo. Cardoso et al. (2003) avaliaram a distribuição vertical de esporos de fungos MAs em cafeeiro sob sombreamento (Tabebuia serratifolia e Schizolobium parahyba) e monocultura, e obtiveram maior densidade de esporos na camada subsuperficiale sistemas agroflorestais $(40-60 \mathrm{~cm})$, em que havia maior número de raízes, quando comparada à monocultura, mostrando a ocorrência de micorriza em profundidade, de grande importância no aumento da disponibilidade de $\mathrm{P}$ ao cafeeiro e melhorias no processo de ciclagem de P. d Outros estudos seriam interessantes para comprovar a variação na distribuição da densidade de esporos nestes sistemas e, diretamente, a formação de micorriza em cafeeiro, em maior profundidade. Outra hipótese pode estar relacionada ao fato de que baixo teor de P remanescente, baixa porcentagem de soma de bases e melhores condições físicas (porosidade 
total e densidade do solo) foram observados no sistema CSM, contribuindo positivamente para maior colonização micorrízica dos cafeeiros.

TABELA 2: Médias dos atributos microbiológicos e bioquímicos do solo sob sistema agroflorestal café-araucária e café a pleno sol.

TABLE 2: Averages of microbial and biochemical attributes from soil under agroforestry system coffee-araucaria and coffee under full sun.

\begin{tabular}{|c|c|c|c|}
\hline Atributo & $\mathrm{CSM}$ & CSI & $\overline{\mathrm{CSP}}$ \\
\hline Bactérias, $\log \mathrm{NMP} \mathrm{g}^{-1}$ solo seco & $8,59 \mathrm{a}$ & $7,83 \mathrm{a}$ & $\overline{8,64 a}$ \\
\hline Fungos, $\log$ NMP g-1 solo seco & $5,62 \mathrm{a}$ & $6,16 \mathrm{a}$ & $5,93 a$ \\
\hline Celulolíticos, $\log$ NMP g${ }^{-1}$ solo seco & 7,33a & $8,80 \mathrm{a}$ & $10,91 \mathrm{a}$ \\
\hline Amonificantes, $\log$ NMP g ${ }^{-1}$ solo seco & $7,70 \mathrm{a}$ & $7,97 \mathrm{a}$ & $8,01 \mathrm{a}$ \\
\hline Desnitrificantes, $\log$ NMP g-1 solo seco & $8,34 \mathrm{a}$ & $7,29 \mathrm{a}$ & $8,24 \mathrm{a}$ \\
\hline Solubilizadores de fosfato, $\log \mathrm{UFC}^{-1}$ de solo seco & $4,15 \mathrm{a}$ & $3,81 \mathrm{a}$ & $5,83 \mathrm{a}$ \\
\hline Micélio extrarradicular total de fungos MAs, $\mathrm{m} \mathrm{g}^{-1}$ solo seco & $5,63 \mathrm{a}$ & $3,63 b$ & $0,90 \mathrm{c}$ \\
\hline Esporos de fungos MAs, $\mathrm{n}^{\mathrm{o}} 50 \mathrm{~g}^{-1}$ solo & $27,63 \mathrm{~b}$ & $57,48 \mathrm{a}$ & $49,63 \mathrm{a}$ \\
\hline Porcentagem de colonização radicular, (CR) \% & $11,50 \mathrm{a}$ & $6,81 \mathrm{~b}$ & $2,71 \mathrm{c}$ \\
\hline Intensidade de colonização radicular, (ICR) \% & $21,32 \mathrm{a}$ & $18,20 \mathrm{ab}$ & $13,20 \mathrm{~b}$ \\
\hline Atividade microbiana, $\mu \mathrm{g} \mathrm{CO}_{2} \mathrm{~g}$ solo $^{-1}$ & $3,34 \mathrm{~b}$ & $5,15 \mathrm{ab}$ & $6,43 a$ \\
\hline Carbono da biomassa microbiana, $\mu \mathrm{g} \mathrm{g}^{-1}$ de $\mathrm{C}$ no solo & $101,14 b$ & $167,67 \mathrm{a}$ & $173,11 \mathrm{a}$ \\
\hline Quociente metabólico $\left(\mathrm{qCO}_{2}\right), \mu \mathrm{g} \mathrm{CO}_{2} \mu \mathrm{g} \mathrm{C}$ solo ${ }^{-1}$ & $0,033 \mathrm{a}$ & $0,031 \mathrm{a}$ & $0,037 \mathrm{a}$ \\
\hline
\end{tabular}

Médias seguidas de mesma letra na linha não diferem entre si pelo teste de Duncan $(\mathrm{p}<0,05)$. CSM (cafeeiro com sombreamento médio); CSI (cafeeiro com sombreamento intenso); CSP (cafeeiro a sol pleno); NMP (número mais provável); UFC (unidade formadora de colônias); fungos MAs (micorrízicos arbusculares).

Quando em simbiose com as plantas, os fungos MAs otimizam a tolerância das plantas a estresses abióticos (JOHNSON; PFLEGER, 1992), a agregação do solo (MILLER; JASTROW, 1992) e a utilização de água e nutrientes do solo em virtude da maior absorção pelo micélio extrarradicular (SMITH; READ, 1997; MELLONI et al., 1999). Portanto, cafeeiro sob sombreamento mediano pode ser favorecido por tal simbiose em relação aos cafeeiros dos demais sistemas, com ocorrência de efeitos positivos diretos e indiretos no seu crescimento e produção.

Apesar de cobertura vegetal predominante de plantas daninhas na gleba CSP, possivelmente, em virtude do menor micotrofismo dessas espécies, observou-se menor formação de rede micelial. A prevalência de maior número de raízes colonizadas no sistema CSM (Tabela 2), com maior colonização individual como resultado da interação sombreamento-colonização foi também observada por Saggin Júnior e Siqueira (1996), em estudo de cafeeiro adulto na Colômbia, onde o café é cultivado em sistema agroflorestal. Observa-se, ainda, que os valores de porcentagem de colonização obtidos nas glebas sombreadas (11,50 e $6,81 \%$, respectivamente para CSM e CSI) foram estatisticamente superiores ao obtido na CSP $(2,71 \%)$, variação que pode chegar a $80 \%$ em cafeeiros adultos, conforme apresentado por Colozzi Filho e Nogueira (2007).

Em estudo desenvolvido em cafezais no Paraná, o cultivo de leguminosas nas entrelinhas resultou em maior esporulação e diversidade de espécies (COLOZZI FILHO; BALOTA, 1994). Esses resultados corroboram aqueles de Bonfim et al. (2010), os quais observaram maior esporulação (mecanismo de sobrevivência) e colonização radicular em cafeeiro sombreado com grevíleas, em Vitória da ConquistaBA, com mudanças fisiológicas e reflexos diretos no teor de clorofila nas folhas.

Os atributos físicos e químicos do solo (Tabela 1) são importantes para explicar tal resultado, uma vez que os sistemas CSP e CSI apresentaram maiores valores de saturação por bases, indicando menor dependência da planta ao fungo na obtenção de nutrientes, diminuindo, por conseguinte, a micorrização. Tal resultado corrobora dados obtidos por Siqueira e Saggin Júnior (1995), Pouyú-Rojas e Siqueira (2000), Andrade et al. (2009), entre outros que comprovaram o efeito antagônico da fertilidade na ocorrência de micorriza. 
Para os atributos bioquímicos, tanto a atividade microbiana quanto o carbono da biomassa microbiana apresentaram os menores valores no CSM, comparados aos dos demais sistemas. Tal resultado não pode ser explicado pelo teor de matéria orgânica, mas possivelmente pela menor fertilidade do solo sob sombreamento mediano (Tabela 1), como os menores valores de $\mathrm{pH}, \mathrm{SB}, \mathrm{t}$ e V\%. Pode, ainda, estar relacionado ao efeito diferenciado da cobertura vegetal sobre os microrganismos, uma vez que, entre outras interferências, disponibiliza aos microrganismos do solo fontes de carbono de diferentes graus de degradação (VENZKE FILHO et al., 2008). A presença de serapilheira de araucária, aliada à baixa fertilidade do solo sob cafeeiro medianamente sombreado, contribuíram para a baixa atividade e biomassa microbianas, cujos microrganismos podem ter apresentado maior dificuldade de degradação e, consequentemente, de crescimento, por tais limitações químicas.

Paralelamente, o sistema CSP apresenta maiores valores de biomassa quando comparados aos do sombreamento mediano, fato que pode ser justificado pela fitomassa nesse sistema ser de composição herbácea, proveniente de plantas daninhas, de mais fácil decomposição. Os sistemas sombreados exercem importante influência no desenvolvimento de plantas daninhas. Nestel e Altieri (1992) concluíram, nesse sentido, que a presença de sombreamento leva a uma menor taxa de incremento de biomassa de plantas daninhas, o que contribui para a baixa presença destas espécies em cafeeiro sombreado.

Comparando-se os resultados de carbono da biomassa microbiana (de 101,14 a 173,11 $\mu \mathrm{g} \mathrm{g}^{-1}$ solo) com aqueles obtidos por Theodoro (2006), de 247,04 $\mu \mathrm{g} \mathrm{g}^{-1}$ solo, em lavoura de café com cultivo orgânico e de $238,50 \mu \mathrm{g} \mathrm{g}^{-1}$ solo para o plantio convencional, verifica-se que os valores encontrados no presente trabalho são inferiores. Altos valores de carbono microbiano foram também obtidos por Martins (2003) em três diferentes agroecossistemas de café, com médias que variaram entre 289 e $328 \mu \mathrm{g} \mathrm{g}^{-1}$ solo.

Para a atividade microbiana, os valores encontrados por Martins (2003) variaram entre 2,2 e 4,5 $\mu \mathrm{g} \mathrm{CO}_{2} \mathrm{~g}^{-1}$ solo, próximos àqueles obtidos no presente trabalho (de 3,34 a $6,43 \mu \mathrm{g} \mathrm{CO}_{2} \mathrm{~g}^{-1}$ solo). Levandose em conta a relação entre atividade microbiana e o carbono da biomassa microbiana, conhecida como quociente metabólico $\left(q \mathrm{CO}_{2}\right)$, foram obtidos os valores de 0,$037 ; 0,033$ e 0,031 para as glebas CSP, CSM e CSI. A ausência de variação dos valores de $q \mathrm{CO}_{2}$ contraria os observados pelo autor supracitado em cafeeiro cultivado com grande diversidade de espécies (bananeira, mamona, pau-pereira, entre outras de crescimento espontâneo) e por outros como Pimentel et al. (2011), estudando o efeito de diferentes sistemas de cultivo orgânico do cafeeiro sobre as características químicas e biológicas do solo, em diferentes estações do ano. Nesse caso, verificaram que houve aumento na atividade microbiana do solo e no $q \mathrm{CO}_{2}$ no verão, em virtude da maior temperatura e incidência de chuvas. No entanto, não observaram diferenças significativas entre as áreas quanto à atividade microbiana, apesar do $q \mathrm{CO}_{2}$ ser maior nos sistemas com até três linhas de guandu (Cajanus cajan) e em área de floresta secundária, e do maior valor de carbono da biomassa microbiana em sistema convencional de pimentão e feijão-vagem. Segundo Ricci et al. (2006), a presença de espécies sombreadoras implicaria em maior ciclagem de nutrientes pela adição constante de material orgânico, maior proteção do solo à radiação solar e maior presença de raízes, aumentando a atividade biológica do solo. No entanto, tal efeito foi também evidenciado na gleba CSP, provavelmente em virtude da maior cobertura do solo com plantas daninhas, conforme já discutido.

Silva et al. (2012), avaliando atributos microbianos em Cambissolo Háplico Tb distrófico típico sob diferentes sistemas agrícolas e florestais no Médio Vale do Paraíba do Sul, Rio de Janeiro, comprovaram relações positivas entre carbono orgânico total dos sistemas e respiração basal, atividade de enzimas e biomassa microbiana, com maiores valores para os sistemas florestais. No presente trabalho, a adição de matéria orgânica pelo cafeeiro e plantas daninhas, independentemente da araucária, contribuiu para manter a microbiota do solo ativa. Tal fato pode estar relacionado ao fato de que a cultura é permanente, com aporte sentidocontínuo de serapilheira, aliado ao baixo revolvimento, o que diminui a taxa de mineralização (CUNHA et al., 2012) e à preservação de maior umidade do solo, estimulando sua microbiota (MATSUOKA; MENDES; LOUREIRO, 2003; PEREZ; RAMOS; MCMANUS, 2004).

Silva et al. (2010), estudando diferentes sistemas de manejo de solos agrícolas e Cerrado, na região Campos das Vertentes, Minas Gerais, também comprovaram a grande influência dos mesmos nos atributos microbianos biomassa e atividade microbiana, com maiores valores no Cerrado nativo, no qual se observou maior teor de carbono orgânico do solo. 
Os resultados da análise multivariada mostraram que os componentes principais 1 e 2 representaram $65,21 \%$ da variância total dos atributos e, por isso, somente estes foram mostrados (Figura 1). Verifica-se a separação espacial do CSM em relação aos demais sistemas agroflorestais (CSI e CSP), em virtude dos menores valores de atributos químicos ligados à fertilidade e melhor estruturação física (densidade do solo, porosidade total), possivelmente relacionada ao maior teor de matéria orgânica, conforme resultados apresentados na Tabela 1 .

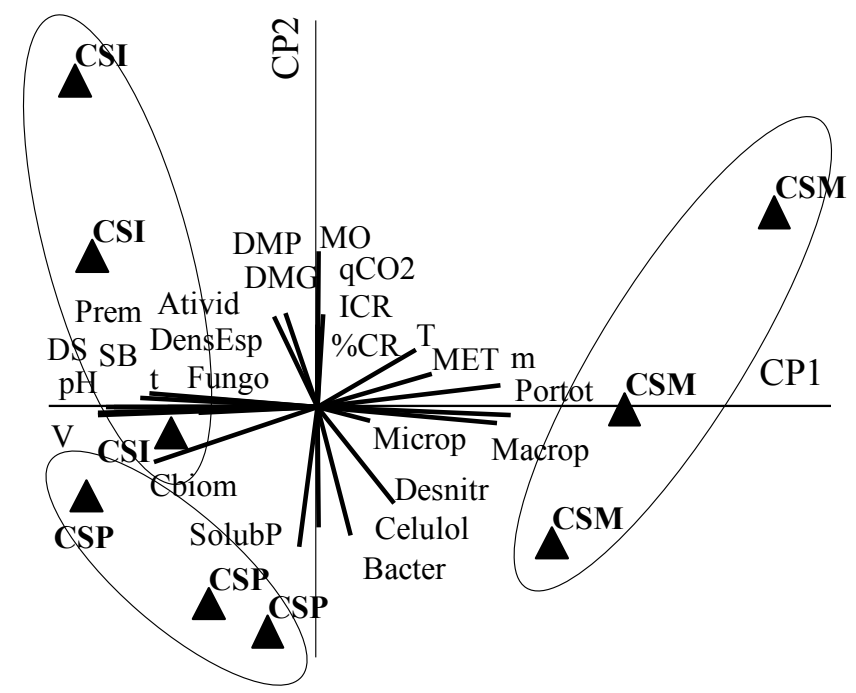

FIGURA 1: Análise de componentes principais das repetições dos atributos microbiológicos, bioquímicos, físicos e químicos para sistemas agroflorestais café-araucária e café a pleno sol. Bacter-bactérias, Fungo-fungos, SolubP-solubilizadores de fosfato, Celulol-celulolíticos, Desnitr-desnitrificantes, ICR-intensidade de colonização radicular, \%CR-porcentagem de colonização radicular, DensEsp-densidade de esporos e MET-comprimento de micélio extrarradicular total de fungos micorrízicos), Ativid-atividade microbiana, Cbiom-carbono da biomassa microbiana, $q \mathrm{CO}_{2}$, DS-densidade do solo, Portot-porosidade total, Micropmicroporosidade, Macrop-macroporosidade, DMP-diâmetro médio ponderado, DMG-diâmetro médio geométrico de agregados, MO-matéria orgânica, pH, Prem, V-saturação por bases, SB-soma de bases t-capacidade de troca catiônica efetiva, T-capacidade de troca catiônica potencial, m-saturação por alumínio, CSI-cafeeiro com sombreamento intenso, CSM-cafeeiro com sombreamento médio, CSPcafeeiro a sol pleno.

FIGURE 1: Principal component analysis for replicates of the microbial, biochemical, physical and chemical attributes under agroforestry system coffee-araucaria and coffee under full sun. Bacter- bacteria, Fungo-fungi, SolubPphosphate solubilizing, Celulol-cellulolytic microorganisms, Desnitr-denitrifying, ICR- intensity of root colonization, \%CR-root colonization percentage, DensEsp- density of fungal spores, MET-total length of extraradical mycelium of arbuscular mycorrhizal fungi), biochemical (Ativid-microbial activity, Cbiommicrobial biomass carbon, $q \mathrm{CO}_{2}$ ), physical (DS-bulk soil, Portot-total porosity, Microp-microporosity, Macrop-Macroporosity, DMP-weighted mean diameter of aggregates, DMG-geometric mean diameter of aggregates) and chemical attributes (MO-organic matter, $\mathrm{pH}$, Prem-P remanescent, V-base saturation, SBsum of bases, t-actual cation exchange capacity, T-total cation exchange capacity, m-Al saturation, CSIunder intense shading with araucária, CSM-under median shading, CSP-coffee under full sun.

Possivelmente, em função da baixa fertilidade dos solos sob CSM (Tabela 1), maiores valores de comprimento de micélio extrarradicular total de fungos MAs e, consequentemente, colonização micorrízica (tanto porcentagem quanto intensidade) do cafeeiro foram obtidos nesse sistema (Tabela 2), comprovandose o efeito inverso da fertilidade na colonização micorrízica. Houve uma relação oposta entre densidade de esporos de fungos MAs e comprimento de MET e colonização micorrízica (Figura 1), conforme já discutido anteriormente.

Os sistemas CSI e CSP, apesar de melhor fertilidade, com maiores valores de $\mathrm{pH}, \mathrm{SB}, \mathrm{P}$ rem, $\mathrm{t}$ e V (Tabela 1), apresentaram maiores valores de DS em relação ao CSM, mas sem afetar sua qualidade 
microbiológica, a qual mostrou maiores valores de atividade e carbono da biomassa microbianas, além de densidade de fungos totais e solubilizadores de fosfato (Figura 1). Contrariamente, o sistema CSM, em função da menor fertilidade do solo (Tabela 1), apresentou plantas com maior colonização radicular (ICR e \%CR), o que proporciona maior resistência vegetal às condições edafoclimáticas e, consequentemente, maior sustentabilidade ambiental com menores exigências físico-químicas do solo (VALADARES; MESCOLOTTI; CARDOSO, 2016). Alia-se ao fato de que, em SAFs, pode-se contar com fontes alternativas de renda, provenientes dos produtos da araucária, libertando o produto das variações cíclicas das cotações de café (BREGONCI; PELISSARI, 1995).

\section{CONCLUSÕES}

O sistema agroflorestal cafeeiro-araucária não afetou a distribuição dos grupos microbianos estudados, mas o sombreamento mediano proporcionou maior acúmulo de matéria orgânica no solo, com efeito positivo nos seus atributos físicos e maior formação de micorriza em cafeeiro.

\section{AGRADECIMENTOS}

À Fundação de Amparo à Pesquisa do Estado de Minas Gerais (Fapemig) pelo apoio.

\section{REFERÊNCIAS}

ANDRADE, S. A. L. et al. Arbuscular mycorrhizal association in coffee. Journal of Agricultural Science, Toronto, v. 147, p. 105-115, 2009.

ANDREAZZA, R. et al. Ocorrência de associação micorrízica em seis essências florestais nativas do estado do Rio Grande do Sul. Ciência Florestal, Santa Maria, v. 18, n. 3, p. 339-346, 2008.

BABBAR, L. I.;ZAK, D. R. Nitrogen cycling in coffee agroecosystems: net N mineralization and nitrification in presence and absence of shade trees. Agriculture, Ecosystems \& Environment, Amsterdam, v. 48, p. 107-113, 1994.

BAYER, C.; MIELNICZUK, J. Dinâmica e Função da Matéria Orgânica. In: SANTOS, G. A.; CAMARGO, F. A. O. Fundamentos da matéria orgânica do solo: ecossistemas tropicais e subtropicais. 2. ed. Porto Alegre: Metrópole, 2008. p. 13-14.

BAYER, C.; MIELNICZUK, J. Dinâmica e função da matéria orgânica. In: SANTOS, G. A.; CAMARGO, F. A. O. Fundamentos da matéria orgânica do solo: ecossistemas tropicais e subtropicais. 2. ed. Porto Alegre: Metrópole, 2008. p. 13-14.

BONFIM, J. A. et al. Fungos micorrízicos arbusculares (FMA) e aspectos fisiológicos em cafeeiros cultivados em sistema agroflorestal e a pleno sol. Bragantia, Campinas, v. 69, n. 1, p. 201-206, 2010.

BREGONCI, I. S.; PELISSARI, S. A. Arborização, quebra-ventos e culturas intercalares. In: COSTA, E. B. (Coord.). Manual técnico para a cultura do café no Estado do Espírito Santo. Vitória: SEAG-ES, 1995. p. 63-67.

CARDOSO, I. M. et al. Distribution of mycorrhizal fungal spores in soils under agroforestry and monocultural coffee systems in Brazil. Agroforestry System, Amsterdam, v. 58, p. 33-43, 2003.

CARNEIRO, M. A. C. et al. Carbono orgânico, nitrogênio total, biomassa e atividade microbiana do solo em duas cronossequências de reabilitação após a mineração de bauxita. Revista Brasileira de Ciência do Solo, Viçosa, MG, v. 32, p. 621-632, 2008.

CHAMORRO, T. G.; GALLO, C. A.; LÓPEZ, A. R. Evaluacion economica del sistema agroflorestal cafe associado com nogal. Cenicafé, Manizales, v. 45, n. 4, p. 164-70, 1994.

COLOZZI FILHO, A; BALOTA, E. L. Potencial de inóculo de fungos micorrízicos arbusculares em solo cultivado com cafeeiro e leguminosas de verão. In: REUNIÃO BRASILEIRA SOBRE MICORRIZAS, 5., 
COLOZZI FILHO, A. et al. Alterações na biomassa microbiana do solo e em alguns de seus componentes, em função da adubação verde do cafeeiro. In: SIMPÓSIO DE PESQUISA DOS CAFÉS DO BRASIL, 1., 2000, Poços de Caldas. Resumos Expandidos... Brasília: EMBRAPA CAFÉ; MINASPLAN, 2000. p. 1393-1395.

COLOZZI FILHO, A.; NOGUEIRA, M. A. Micorrizas arbusculares em plantas tropicais: café, mandioca e cana-de-açúcar. In: SILVEIRA, A. P. D.; FREITAS, S. F. (Ed.). Microbiota do Solo e Qualidade Ambiental. Campinas: Instituto Agronômico, 2007. p. 39-56.

COMISSÃO DE FERTILIDADE DO SOLO DO ESTADO DE MINAS GERAIS. Recomendações para o uso de corretivos e fertilizantes em Minas Gerais: 5. ed. Viçosa, MG: Embrapa; UFV; SBCS, 1999. $359 \mathrm{p}$.

CORREIA, M. E. F.; ANDRADE, A. G. Formação de Serapilheira e Ciclagem de Nutrientes. In: SANTOS, G. A.; CAMARGO, F. A. O. Fundamentos da matéria orgânica do solo: ecossistemas tropicais e subtropicais. 2. ed. Porto Alegre: Metrópole, 2004. p.137-154.

CUNHA, E. Q. et al. Atributos físicos, químicos e biológicos de solo sob produção orgânica impactados por sistemas de cultivo. Revista Brasileira de Engenharia Agrícola e Ambiental, Campina Grande, v. 16, p. 56-63, 2012.

CUNHA, R. L. et al. Biomassa e atividade microbiana em Latossolo Vermelho Distroférrico sob cafeeiro em sistema convencional e orgânico. In: CONGRESSO BRASILEIRO DE PESQUISAS CAFEEIRAS, 31., 2005, Guarapari. Anais... Rio de Janeiro: MAA; PROCAFÉ, 2005. p. 366-367.

DORAN, J. W.; ZEISS, M. R. Soil health and sustainability: managing the biotic component of soil quality. Applied Soil Ecology, Amsterdam, v. 15, n. 1, p. 3-11, 2000.

EMBRAPA. Manual de métodos de análise de solo. Rio de Janeiro: Ministério da Agricultura e do Abastecimento, 1997. $212 \mathrm{p}$.

FASSBENDER, H.W. Modelos edafológicos de los sistemas de producción agroflorestales. 2 ed. Turrialba: Centro Agronômico Tropical de investigación y Enseñanza, 1993. 530 p.

GAMA RODRIGUES, A. C. Sistemas agroflorestais: bases científicas para o desenvolvimento sustentável. Campos dos Goytacazes: Universidade Estadual do Norte Fluminense Darcy Ribeiro, 2006.

HAAG, P. H. Ciclagem de nutrientes em florestas tropicais. Campinas: Fundação Cargill, 1975. 144 p. ILANY, T. et al. Using Agroforestry to improve soil fertility: efects of intercropping on Ilex paraguariensis (yerba mate) plantations with Araucaria angustifolia. Agroforest Systems, Amsterdam, v. 80, p. 399-409, 2010.

JOHNSON, N. C.; PFLEGER, F. L. Vesicular-arbuscular mycorrhiza and cultural stresses. In: BETHLENFALVAY, G. J.; LINDERMAN, R. G. (Ed.). Mycorrhizae in sustainable agriculture. Madison: American Society of Agronomy, 1992. p. 71-99.

LUNZ, A. M. P. Crescimento e produtividade do cafeeiro sombreado e a pleno sol. $2006.95 \mathrm{f}$. Tese (Doutorado) - Universidade de São Paulo: Escola Superior de Agricultura, Piracicaba, 2006.

MARTINS, M. Caracterização de sistemas orgânicos de produção de café utilizados por agricultores familiares em Poço Fundo, MG. 2003. 190 f. Tese (Doutorado) - Universidade Federal de Lavras, Lavras, 2003.

MATIELLO, J. B. Sistemas de produção na cafeicultura moderna: tecnologias de plantio adensado, renque mecanizado, arborização e recuperação de cafezais. Rio de Janeiro: MM Produções Gráficas, 1995. $102 \mathrm{p}$.

MATIELLO, J. B. et al. Observações sobre nível de sombreamento em lavoura cafeeira em Pernambuco. In: CONGRESSO BRASILEIRO DE PESQUISAS CAFEEIRAS, 12., Caxambu, 1985. Anais... Rio de Janeiro: MIC; IBC, 1985. p. 14-15.

MATSUMOTO, S. N. Arborização de cafezais no Brasil. Vitória da Conquista: Edições UESB, 2004. $213 \mathrm{p}$. 
MATSUOKA, M.; MENDES, L. C.; LOUREIRO, M. F. Biomassa microbiana e atividade enzimática em solos sob vegetação nativa e sistemas agrícolas anuais e perenes na região de Primavera do Leste (MT). Revista Brasileira de Ciência do Solo, Viçosa, MG, v. 7, p. 425-433, 2003.

MELLONI, R. et al. Avaliação da qualidade de solos sob diferentes coberturas florestais e de pastagem no sul de Minas Gerais. Revista Brasileira de Ciência do Solo, Viçosa, MG, v. 32, p. 2461-2470, 2008.

MELLONI, R. et al. Características biológicas de solos sob mata ciliar e campo cerrado no sul de Minas Gerais. Ciência e Agrotecnologia, Lavras, v. 25, p. 7-13, 2001.

MELLONI, R. et al. Métodos de controle de plantas daninhas e seus impactos na qualidade microbiana de solo sob cafeeiro. Revista Brasileira de Ciência do Solo, Viçosa, MG, v. 37, p. 66-75, 2013.

MELLONI, R.; CARDOSO, E. J. B. N. Quantificação de micélio extrarradicular de fungos micorrízicos arbusculares em plantas cítricas - II: comparação entre diferentes espécies cítricas e endófitos. Revista Brasileira de Ciência do Solo, Viçosa, MG, v. 23, n. 1, p. 59- 67, jan./mar. 1999.

MELLONI, R.; SIQUEIRA, J. O.; MOREIRA, F. M. S. Fungos micorrízicos arbusculares em solos de área de mineração de bauxita em reabilitação. Pesquisa Agropecuária Brasileira, Brasília, v. 38, n. 2, p. $267-$ 276, 2003.

MILLER, R. M.; JASTROW, J. D. The application of VA Mycorrhizae to ecossystem restoration and reclamation. In: ALLEN, M. J. (Ed.). Mycorrhizal functioning-an integrative plant-fungal process. New York: Chapman \& Hall, 1992. p. 439-467.

MOREIRA-SOUZA, M.; CARDOSO, E. J. B. N. Dependência micorrízica de Araucaria angustifolia (Bert.) O. Ktze. sob níveis de fósforo. Revista Brasileira de Ciência do Solo, Viçosa, MG, v. 26, p. 905912, 2002.

MOREIRA-SOUZA, M. et al. Arbuscular mycorrhizal fungi associated with Araucaria angustifolia (Bert.) O. Ktze. Mycorrhiza, New York, v. 13, p. 211-215, 2003.

NESTEL, D.; ALTIERI, M. A. The weed community of Mexican coffee agroecosystems: effect of management upon plant biomass and species composition. Acta Ecologica, Amsterdam, v. 13, n. 6, p. 715726, 1992.

OLIVEIRA, C. C. et al. Sombreamento de café (Coffea arabica L.) por araucária (Araucaria angustifolia L.) e seus efeitos na macrofauna e atributos físicos do solo. Revista Brasileira de Geografia Física, Recife, v. 9, n. 6, p. 1668-1676, 2016.

PEREZ, K. S.; RAMOS, M. L. G.; MCMANUS, C. Carbono da biomassa microbiana em solo cultivado com soja sob diferentes sistemas de manejo nos Cerrados. Pesquisa Agropecuária Brasileira, Brasília, v. 39, p. 567-573, 2004.

PIMENTEL, M. S. et al. Bioindicators of soil quality in coffee organic cultivation systems. Pesquisa Agropecuária Brasileira, Brasília, v. 46, n. 5, p. 546-553, 2011.

POUYÚ-ROJAS, E.; SIQUEIRA, J. O. Micorriza arbuscular e fertilização do solo no desenvolvimento pós-transplante de mudas de sete espécies florestais. Pesquisa Agropecuária Brasileira, Brasília, v. 35, p. 103-114, 2000.

RICCI, M. S. F. et al. Cultivo orgânico de cultivares de café a pleno sol e sombreado. Pesquisa Agropecuária Brasileira, Brasília, v. 41, p. 569-575, 2006.

SAGGIN JÚNIOR, O. J.; SIQUEIRA, J. O. Micorrizas arbusculares em cafeeiro. In: SIQUEIRA, J. O. (Ed.). Avanços em fundamentos e aplicação de micorrizas. Lavras: Universidade Federal de Lavras, 1996. p. 203-254.

SEVERINO, L. S.; OLIVEIRA, T. S. Sistema de cultivo sombreado do cafeeiro (Coffea arabica L.) na região de Baturité, Ceará. Revista Ceres, Viçosa, MG, v. 46, p. 635-652, 1999.

SILVA, C. F. et al. Carbono orgânico total, biomassa microbiana e atividade enzimática do solo de áreas agrícolas, florestais e pastagem no médio Vale do Paraíba do Sul (RJ). Revista Brasileira de Ciência do Solo, Viçosa, MG, v. 36, n. 6, p. 1680-1689, 2012.

SILVA, R. R. et al. Biomassa e atividade microbiana em solo sob diferentes sistemas de manejo na região fisiográfica Campos das Vertentes - MG. Revista Brasileira de Ciência do Solo, Viçosa, MG, v. 34, n. 5 , p. 1585-1592, 2010. 
SIQUEIRA J. O.; SAGGIN JÚNIOR, O. J. The importance of mycorrhizae association in natural lowfertility soils. In: MACHADO, A. T. et al. Proceedings International Symposium on Environmental Stress: Maize in Perspective. Brazil/México. [s. 1.]: EMBRAPA; CYMMYT; UNDT, 1995. p. 240-280.

SMITH, S. E.; READ, D. J. Mycorrhizal symbiosis. 2nd. ed. London: Academic Press, 1997. 605 p. THEODORO, V. C. A. Transição do manejop de lavoura cafeeira do sistema convencional para o orgânico. 2006. 142 f. Tese (Doutorado) - Universidade Federal de Lavras, Lavras, 2006.

ULBRICH, A. V. et al. Ação do imazapic+imapyr sobre a tiririca (Cyperus rotundus) e os desnitrificantes em milho. Planta Daninha, Viçosa, MG, v. 22, p. 577-582, 2004.

VALADARES, R. B. S.; MESCOLOTTI, D. L. C.; CARDOSO, E. J. B. N. Micorrizas. In: CARDOSO, E. J. B. N.; ANDREOTE, F. D. Microbiologia do solo. 2. ed. Piracicaba: Esalq, 2016. p. 179-196.

VENZKE FILHO, S. P. et al. Biomassa microbiana do solo em sistema de plantio direto na região de Campos Gerais - Ribagi, PR. Revista Brasileira de Ciência do Solo, Viçosa, MG, v. 32, p. 599-610, 2008. WOHLENBERG, E. V. et al. Dinâmica da agregação de um solo franco-arenoso em cinco sistemas de culturas em rotação e em sucessão. Revista Brasileira de Ciência do Solo, Viçosa, MG, v. 28, p. 891-900, 2004.

YOUNG, A. Tropical soils and soil survey. Cambridge: Cambridge University Press, 1976. 468 p.

ZANGARO, W. et al. Root mycorrhizal colonization and plant responsiveness are related to root plasticity, soil fertility and successional status of native woody species in southern Brazil. Journal of Tropical Ecology, Cambridge, v. 23, p. 53-62, 2007. 